\title{
How and Why to Manage 3D Printing Process?
}

\author{
Magdalena BARBU \\ Transilvania University of Brasov, Romania, magda.n@unitbv.ro \\ Catrina CHIVU \\ Transilvania University of Brasov, Romania, catrina.c@unitbv.ro
}

\begin{abstract}
The present paper is focused on identify the main conditions that should be followed to obtain an optimum threedimensional (3D) printing, starting with the 3D design software, to printers and characteristics. The purpose of the analysis is to be able to develop an informatic instrument, designed for choosing the appropriate 3D printing characteristics, printers and materials based on the purpose and industry of the printed part. Because the input data are very diverse, with multiple options and the user either has one specific printer, or want a specific material, authors implement fuzzy logic in obtaining the optimum. Since there is no such software on the market, it is believed that the informatic application developed by authors can help the decision makers about their 3D printing process.
\end{abstract}

\section{Keywords}

3D printing, printer, Industry 4.0, fuzzy logic

\section{Introduction in Three-Dimensional Printing: Process and Oriented Software \\ 1.1. Three-dimensional printing process}

Three-dimensional (3D) printing is an additive manufacturing, based on successive layers forming. The development of 3D printing started in 1980s and evolved from prototyping to mass customization and mass production [1]. Additive manufacturing also allows a more transparent and efficient collaboration between the final product manufacturer and the customer, thus helping to reorganize the supply chain. Additive manufacturing gives customers the flexibility to make their products according to their needs. As the additive manufacturing becomes more and more used in the realization of physical objects and proves to be a process that offers safety, it is aimed at its final introduction in series production

Based on literature [1], there are seven categories of processes for additive manufacturing (Fig. 1).

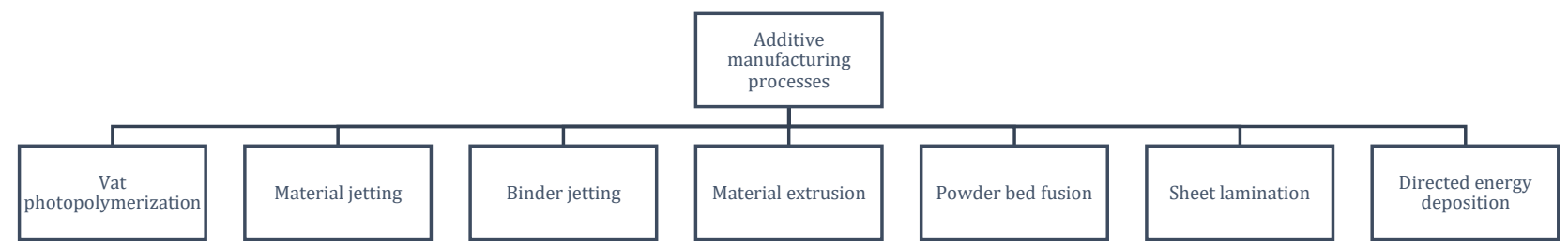

Fig. 1. Additive manufacturing processes categories (adapted from [1])

Three-dimensional printing allow users to obtain very complex shapes, based on CAD drawings. Fortunately, todays CAD/ CAM software allow direct connection between 3D model and 3D printers, exporting files in *.stl/ ${ }^{*} . \mathrm{obj} /{ }^{*}$.vrml $/{ }^{*}$.ply formats. The main idea of 3D printing is creating a 3D models database. This database may be obtain from: CAD/ CAM oriented program, medical devises (as tomographic scanner), anthropometric measurement devices or 3D scanners.

The 3D technologies differ based on raw materials (resin, metal, gypsum or sand) and applied principles. Thus, there are: fused deposition modelling (FDM), stereolithography (SLA), masked stereolithography (MSLA), digital light processing (DLP), selective laser sintering (SLS), direct metal laser sintering (DMLS), selective laser melting (SLM), electron beam melting (EBM), drop-on demand (DOD) [1]. 
The main advantage of 3D printing is the complex shape that may be obtained but there are a few disadvantages that determined this method of manufacturing not being applied as much as desired. Along these disadvantages should be mentioned:

- time-consuming for design objects and to manufacture products; this determines law of productivity of the method;

- limited types of raw materials that should be used, restricting the fields that may use such a manufacturing method;

- low precision of the final product, precision being a correlation between 3D drawing processing time, printing time, material consumption, material type.

Considering these negative aspects and based on literature there may be formulated some solutions that will sustain the idea of the authors: developing an informatic solution that optimise the whole 3D printing process (Table 1). The application will be designed for both the beginners in 3D printing and for company' specialists that want to implement additive manufacturing.

Table 1. Solutions for 3D printing negative issues (adapted from [1])

\begin{tabular}{|l|l|}
\hline 3D printing challenges & Solutions \\
\hline $\begin{array}{c}\text { Time consumption } \\
\text { (3D design) }\end{array}$ & $\begin{array}{l}\text { - create 3D object database; } \\
\text { - find exact product in existing databases; } \\
\text { - find the most similar product in existing databases }\end{array}$ \\
\hline $\begin{array}{l}\text { Time consumption } \\
\text { (3D printing) }\end{array}$ & $\begin{array}{l}\text { - identifying the optimum printer and printing parameters for each } \\
\text { type of product; }\end{array}$ \\
\hline Low productivity & $\begin{array}{l}\text { - large 3D object database that reduce or even eliminate design time; } \\
\text { - optimum printer, printing parameters, selection of optimum material } \\
\text { based on the industry/ field of the product }\end{array}$ \\
\hline $\begin{array}{l}\text { Intellectual property rights } \\
\text { of 3D printing }\end{array}$ & $\begin{array}{l}\text { - large 3D object model database (free or partially free), managed by } \\
\text { an independent company, generating a hub that receives a } \\
\text { commission }\end{array}$ \\
\hline
\end{tabular}

\subsection{Three-dimensional printing software}

Considering 3D printing software there are two categories: first, oriented on computer aided design and second is focused on 3D modelling. Even if it looks like we are talking about the same idea, first category is most used in automotive, aerospace and aeronautics fields, in other words whenever the mechanical properties of the final products is very important. The second category is more and artistic one, focused on getting objects with aesthetic value more than a functional one. In the following authors concentrate on the first category of software.

Before starting 3D printing it is mandatory to know that there are three types of software that are needed: a CAD one (that helps to obtain the 3D design), a slicer (a pre-print software that connects the CAD software and the printer one, preparing the 3D design to be printed), and the printer software (Table 2).

All the analyses of 3D printing software have the result that, actually, there is no software that may help user to identify optimum characteristics of additive manufacturing process. This software may help users to save time and it should give information regarding also the CAD software and printer that should be used based on the product field.

\section{Three-Dimensional Printing in the Context of Actual Industry}

The idea of developing an informatic application designed for 3D printing should be validated by a feasibility study. This study was done by analysing the opportunity and perspective of this additive manufacturing process in the context of massive development of CNC machining and inherent implementation Industry 4.0. Industry 4.0 aims are to achieve a close link between man, product, process and intelligent system. The main features of Industry 4.0 are interconnection, transparency of information, technical assistance and decentralized decisions. Industry 4.0 also considers environmentally sustainable production. 
RECENT, Vol. 22, no. 3(65), 2021

Table 2. Software on the market (adapted from $[2,3,4,5]$ )

\begin{tabular}{|l|l|l|}
\hline Software & Type of software & Characteristics \\
\hline Autodesk Fusion 360 & $\begin{array}{l}\text { 3D design, 3D printing, } \\
\text { slicer }\end{array}$ & $\begin{array}{l}\text { - used in automotive, mechanical engineering; } \\
\text { - complex shapes; }\end{array}$ \\
\hline Autodesk AutoCAD & 3D design & $\begin{array}{l}\text { - used in different fields; } \\
\text { - complex shapes; }\end{array}$ \\
\hline Siemens NX & 3D design, 3D printing & $\begin{array}{l}\text { - used in different fields; } \\
\text { - complex shapes; }\end{array}$ \\
\hline Catia & $\begin{array}{l}\text { 3D design, 3D printing, } \\
\text { slicer }\end{array}$ & $\begin{array}{l}\text { - complex shapes; } \\
\text { - multi-platform suite (CAD, CAM, CAE); } \\
\text { - 3DExperience platform; }\end{array}$ \\
\hline Creo & $\begin{array}{l}\text { 3D design, 3D printing, } \\
\text { slicer }\end{array}$ & $\begin{array}{l}\text { - complex shapes; } \\
\text { - multi-platform suite (CAD, CAM, CAE); } \\
\text { - complex tools: motion, structural, thermal, etc.; } \\
\text { - design simulation }\end{array}$ \\
\hline Cura & slicer & Filament \\
\hline PrusaSlicer & slicer & Filament, resin (LCD-based) \\
\hline ideaMaker & slicer & Filament \\
\hline ChiTuBox Basic & slicer & Resin (LCD-based) \\
\hline Lychee Slicer & slicer & Resin (LCD-based) \\
\hline Kiri:Moto & slicer & Filament, resin (LCD-based), CNC \\
\hline IceSL & slicer & Filament \\
\hline MatterControl 2.0 & slicer & Filament \\
\hline AstroPrint & slicer & Filament \\
\hline FreeCAD & slicer & All \\
\hline
\end{tabular}

The need of using additive manufacturing results from the role of designer or product developer from today. Thus, any product should be feasible from economical, social and environmental point of view, thus should be sustainable. This sustainability is gain by using only the necessary amount of material to manufacture the prototype and mass product.

It has to be recognised that 3D printing it is not yet suitable for mass production, being limited in speed and cost of raw materials. In literature, 3D printing is always compare to CNC machining but from prototyping point of view the first one is more appropriate (Table 3 ).

Besides the above data, it is relevant the fact that on the market appear hybrid machines, that combines the two manufacturing technologies (as example can be mentioned, ZMorph $2.0 \mathrm{SX}$, a CNC milling machine and printing).

Table 3. Three-dimensional printing vs CNC machining

\begin{tabular}{|c|c|c|}
\hline \multirow{2}{*}{$\begin{array}{l}\text { Characteristic/ } \\
\text { aspect }\end{array}$} & \multicolumn{2}{|l|}{ Evaluation } \\
\hline & Plus & Minus \\
\hline Waste & $\begin{array}{l}\text { 3D printing }=\text { additive } \\
\text { manufacturing } \Rightarrow Q_{\text {waste }}=\text { small }\end{array}$ & $\begin{array}{l}\text { CNC machining = subtractive manufacturing } \\
\Rightarrow Q_{\text {waste }}=\text { large }\end{array}$ \\
\hline Materials & $\begin{array}{l}\text { CNC machining = cutting process } \\
\Rightarrow \text { any type of material }\end{array}$ & $\begin{array}{l}\text { 3D printing = manufacturing layer by layer } \\
\text { using laser / heated extruder } \Rightarrow \text { few } \\
\text { materials (plastic filaments -FDM- , resins - } \\
\text { SLA/ DLP - , plastic or metal powders - SLS, } \\
\text { DMLS, SLM) }\end{array}$ \\
\hline Processing time & $\begin{array}{l}\text { CNC cutting speed depends on raw } \\
\text { material, tool, type of process, but } \\
\text { it may take values of over } 900 \mathrm{~m} / \\
\text { min for plastics (polyethylene) [6] }\end{array}$ & $\begin{array}{l}\text { the most performant printer can reach print } \\
\text { speed up to } 24 \mathrm{~m} / \mathrm{min} \text { and } 1 \text { meter per second } \\
\text { [7] }\end{array}$ \\
\hline
\end{tabular}


RECENT, Vol. 22, no. 3(65), 2021

\begin{tabular}{|c|c|c|}
\hline \multirow{2}{*}{$\begin{array}{l}\text { Characteristic/ } \\
\text { aspect }\end{array}$} & \multicolumn{2}{|l|}{ Evaluation } \\
\hline & Plus & Minus \\
\hline $\begin{array}{l}\text { Processing } \\
\text { accuracy }\end{array}$ & $\begin{array}{l}\text { CNC machining [8] } \\
\text { - tolerance: } \pm 0.025-0.125 \mathrm{~mm} \text {; } \\
\text { - min. layer thickness: cutting } \\
\text { depth } 0.01 \mathrm{~mm} \text {; } \\
\text { - max. build volume: } \\
\quad 2000 \times 800 \times 1000 \mathrm{~mm}\end{array}$ & $\begin{array}{l}\text { 3D printers: } \\
\text { SLS: - tolerance: } \pm 0.3 \mathrm{~mm} \text {; } \\
\quad \text { - min. layer thickness: } 0.7-1.0 \mathrm{~mm} \text {; } \\
\quad \text { - max. build volume: } 300 \times 300 \times 300 \mathrm{~mm} \\
\text { FDM: - tolerance: } \pm 0.5 \mathrm{~mm} \text {; } \\
\quad \text { - min. layer thickness: } 0.8-1.0 \mathrm{~mm} \text {; } \\
\quad \text { - max. build volume: } 900 \times 600 \times 900 \mathrm{~mm} \\
\text { DMLS: - tolerance: } \pm 0.1 \mathrm{~mm} ; \\
\quad \text { - min. layer thickness: } 0.4 \mathrm{~mm} ; \\
\text { - max. build volume: } 230 \times 150 \times 150 \mathrm{~mm}\end{array}$ \\
\hline Usability & $\begin{array}{l}\text { - 3D printing: user-friendly } \\
\text { interface; no-programming } \\
\text { knowledge needed }\end{array}$ & $\begin{array}{l}\text { - CNC machines: CNC programming } \\
\text { knowledge; } \\
\text { - no tools selection skills needed; } \\
\text { - no cutting parameters knowledge needed }\end{array}$ \\
\hline
\end{tabular}

\section{Factors That Influence the Performance and Quality of 3D Printed Products}

SWOT items (Table 4) highlights the strengths, weaknesses, opportunities and threats of 3D printing technology $[9,10]$.

Table 4. Solutions for 3D printing negative issues (adapted from [10])

\begin{tabular}{|l|l|}
\hline \multicolumn{1}{|c|}{ STRENGTHS } & \multicolumn{1}{c|}{ WEAKNESS } \\
\hline - Increased design flexibility & - Materials are limited \\
- Reduction of material waste & - High cost of printers \\
- Short supply chain & - Speed and volume \\
- Small number of dedicated tools & - Straight of parts \\
- Improved labour costs & - Usability \\
- Available to all & - Lack of control over printers \\
- Positive market growth & - Different quality depending on the printers used \\
- Manufacturing process efficiency & - Learning to use of machine and software \\
- High product quality & - The need for post-processing \\
& - Problems in printing smaller details and larger product \\
\hline \multicolumn{1}{|c|}{ OPPORTUNITIES } & - Requires a controlled environment \\
\hline - Building products can be customized & - Copyright \& ethics \\
- Encourages small production & - Consumer rights \\
- Improved testing of products & - Frivolous printing \\
- New jobs are created & - Job losses (traditional) \\
- Manufacturing process is encouraged & - Machine compatibility and upgrade \\
- Undesirability is eliminated & - Public safety \\
- Increased innovation & - Impact on environment \\
- Customization of existing design & - Intellectual property rights \\
- Active material development & \\
- Introduction of advanced machine & \\
- 4D printing technology &
\end{tabular}

For getting the best quality of the printed part, it must be considered the influence factors such as material properties, machine specifications, printing conditions and process parameters (Fig. 2). 
RECENT, Vol. 22, no. 3(65), 2021

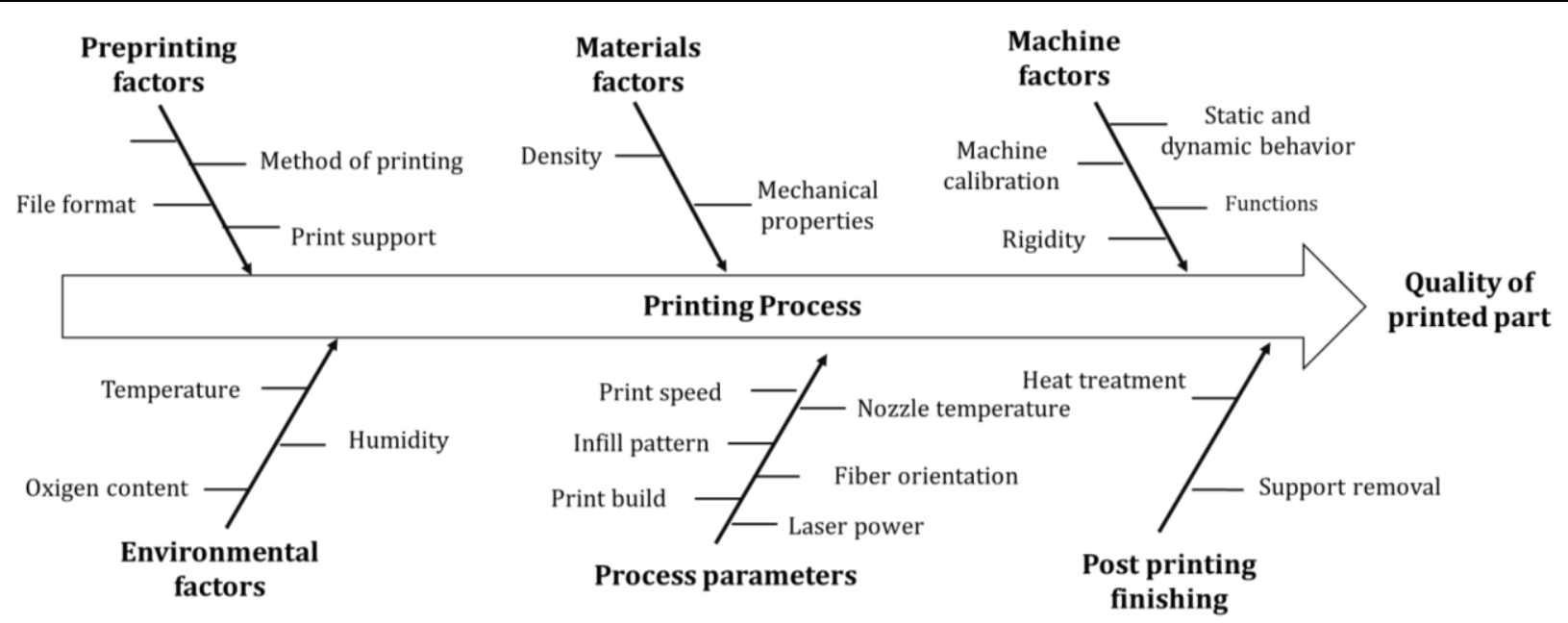

Fig. 2. Ishikawa diagram

To be able to identify the most important factor that influence 3D printing, in the following, a qualitative and quantitative analysis of the risks identified in the 3D printing process will be made (Table 5). First, there are identified and described risk categories: risks regarding the setting of parameters and adjustment, the risks generated due to the equipment; risks regarding the appearance of visual defects risks in the post-processing process.

Table 5. Risk factors

\begin{tabular}{|c|c|}
\hline Risk category & Risk factors \\
\hline \multirow{5}{*}{$\begin{array}{l}\text { Process parameters } \\
\text { settings }\end{array}$} & Nozzle temperature \\
\hline & Platform temperature \\
\hline & Print speed \\
\hline & Machine calibration \\
\hline & Infill type \\
\hline \multirow{7}{*}{$\begin{array}{l}\text { Risks that may occur } \\
\text { during the printing } \\
\text { process }\end{array}$} & Uneven layer \\
\hline & Peeling off layers during printing \\
\hline & Detaching the object from the platform \\
\hline & Imperfect clearances (sharp edges) \\
\hline & Scratches on the surface of the printed object \\
\hline & Discoloration / staining \\
\hline & Imperfect clearances (sharp edges) \\
\hline \multirow{2}{*}{$\begin{array}{l}\text { Risks in the post- } \\
\text { processing process }\end{array}$} & Improper removal of structures from the support \\
\hline & The need for additional operations \\
\hline
\end{tabular}

For each risk factor, scores will be given for the likelihood of occurrence and its impact on quality and technical performance.

The risk score is determined as the product of the risk probability score and the risk impact score. The risk score was determined according to the formula:

$$
R S_{i}=P S_{i} \cdot I S_{i}
$$

where RS - risk score, PS - probability score, SI - impact score, and $i=1,2, \ldots n$, and $n$ represents the number of identified risk factors (Table 6).

The level of risk was determined considering the calculated risk score, as follows:

- $\quad$ Risk level $1 \rightarrow$ very low risk (dark green) $\rightarrow 1 \leq \mathrm{SR} \leq 5$;

- $\quad$ Risk level $2 \rightarrow$ low risk (light green) $\rightarrow 5 \leq \mathrm{SR} \leq 8$;

- $\quad$ Risk level $3 \rightarrow$ moderate risk (yellow) $\rightarrow 10 \leq \mathrm{SR} \leq 20$;

- $\quad$ Risk level $4 \rightarrow$ high risk (orange) $\rightarrow 25 \leq \mathrm{SR} \leq 40$;

- $\quad$ Risk level $5 \rightarrow$ very high risk (red) $\rightarrow 50 \leq \mathrm{SR} \leq 100$. 
RECENT, Vol. 22, no. 3(65), 2021

Table 6. Risk analysis

\begin{tabular}{|c|l|c|c|c|}
\hline $\begin{array}{c}\text { Cod } \\
\text { risk }\end{array}$ & \multicolumn{1}{|c|}{ Risk factors } & $\begin{array}{c}\text { Probability } \\
\text { score (PS) }\end{array}$ & $\begin{array}{c}\text { Impact } \\
\text { score (IS) }\end{array}$ & $\begin{array}{c}\text { Risk } \\
\text { score (RS) }\end{array}$ \\
\hline$R_{1}$ & Nozzle temperature & 1 & 20 & 20 \\
\hline$R_{2}$ & Platform temperature & 1 & 20 & 20 \\
\hline$R_{3}$ & Print speed & 2 & 20 & 40 \\
\hline$R_{4}$ & Machine calibration & 2 & 20 & 40 \\
\hline$R_{5}$ & Infill type & 2 & 10 & 20 \\
\hline$R_{6}$ & Uneven layer & 2 & 20 & 40 \\
\hline$R_{7}$ & Peeling off layers during printing & 3 & 20 & 60 \\
\hline$R_{8}$ & Detaching the object from the platform & 3 & 20 & 60 \\
\hline$R_{9}$ & Imperfect clearances (sharp edges) & 1 & 10 & 10 \\
\hline$R_{10}$ & Scratches on the surface of the printed object & 2 & 10 & 20 \\
\hline$R_{11}$ & Discoloration / staining & 1 & 10 & 10 \\
\hline$R_{12}$ & Imperfect clearances (sharp edges) & 2 & 10 & 20 \\
\hline$R_{13}$ & Improper removal of structures from the support & 3 & 5 & 15 \\
\hline$R_{14}$ & The need for additional operations & 3 & 5 & 15 \\
\hline
\end{tabular}

Based on these assumptions and calculus there may be determined the level of risk for each factor (Fig. 3).

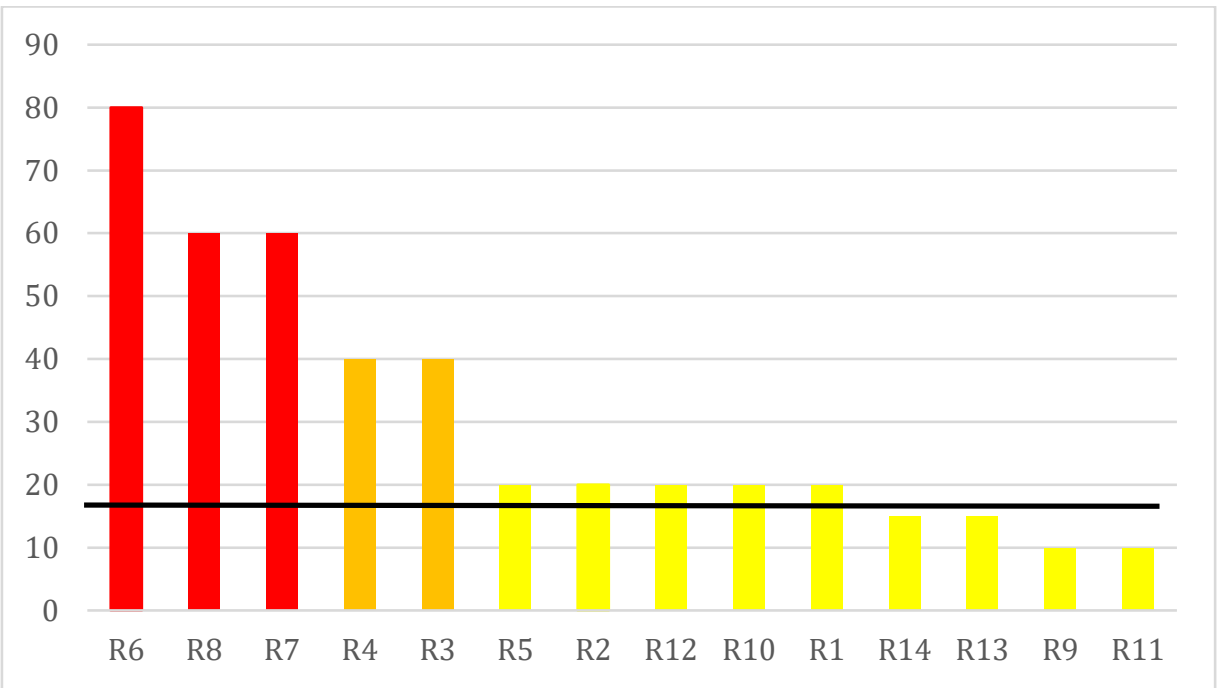

Fig. 3. Level of risk

The analysis shows that the printing parameters setting is extremely important in obtaining high quality printed parts. The existence of an oriented software that indicates the optimal printing parameters is a safe way to reduce these technological risks. Besides this, risk analysis underlined that selection of optimum parameters should be solved using applying multiple selection criteria, with different weights for each criteria and sub-criteria. To obtain this, the most appropriate method is fuzzy logic (in fact, fuzzy analytic hierarchy process).

\section{Informatic Application: Structure and Fuzzy Selection}

The informatic application developed by the authors started as necessity of solving the main problems of 3D printing (Table 1). It will be useful for both beginners and experts that need to optimize additive manufacturing process. The idea of the software is to allow the user to choose desired selection criteria, based on what he wants. Thus, there is a selecting process by functionality of the object, by material, by manufacturing capabilities (Fig. 4). 


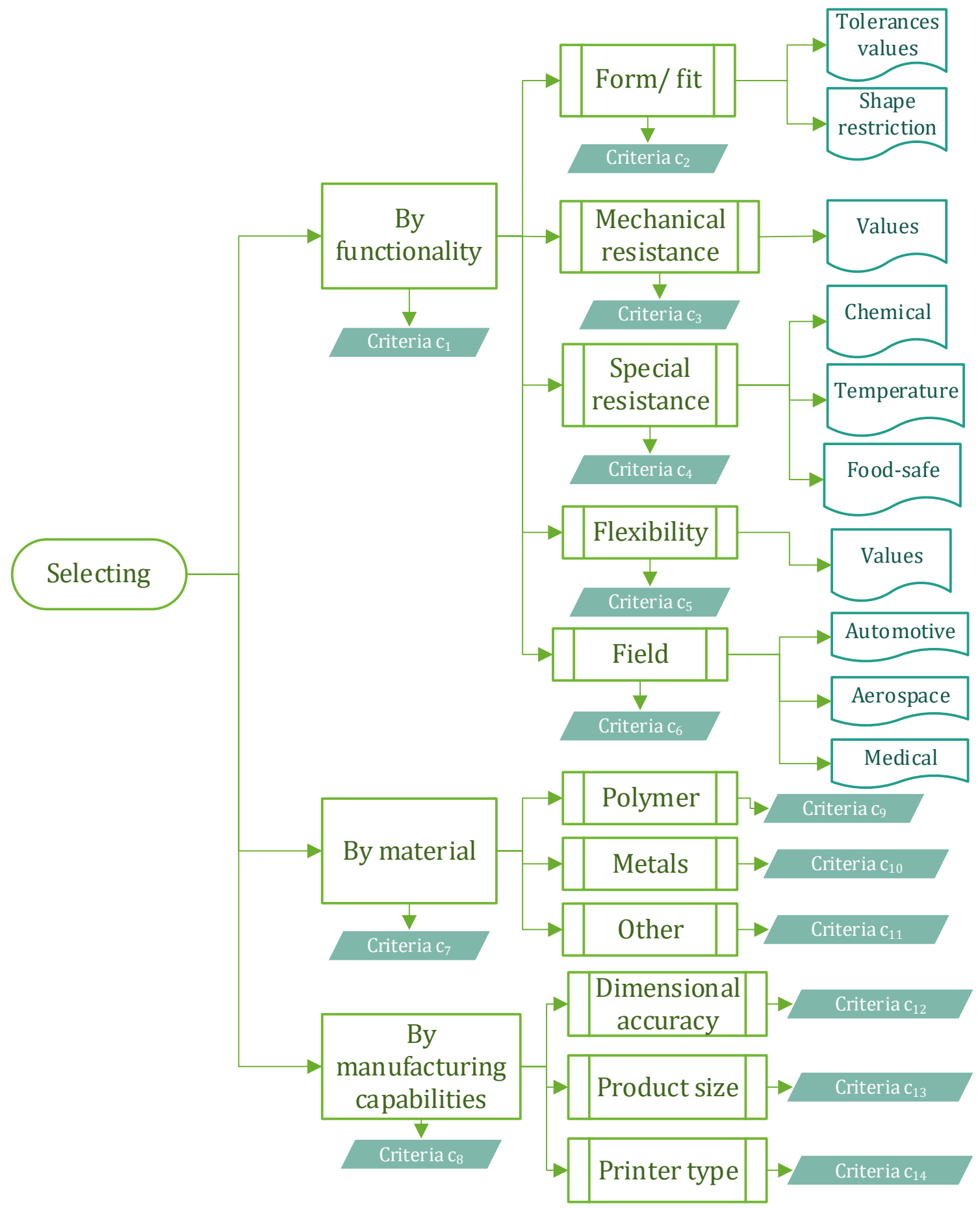

Fig. 4. Structural diagram of informatic application

The above diagram is a principial one, selection being interconnected, for example, if it is chosen selection by functionality $\rightarrow$ mechanical resistance but la value is not known, the user may select material and the values are automatically given. Another example is that when the selection is done by functionality $\rightarrow$ field, after that user may choose from this point another criteria (material or manufacturing capabilities or even resistance).

The structure of informatic application being a cascade one, going from one criteria to another (like the filter principle on web-sites) this multiple selection should be prioritised. The fuzzy logic is implemented to prioritised selection criteria and Preference Ranking Organization METHod for Enrichment of Evaluations method to rank the alternatives (Fig. 5). 


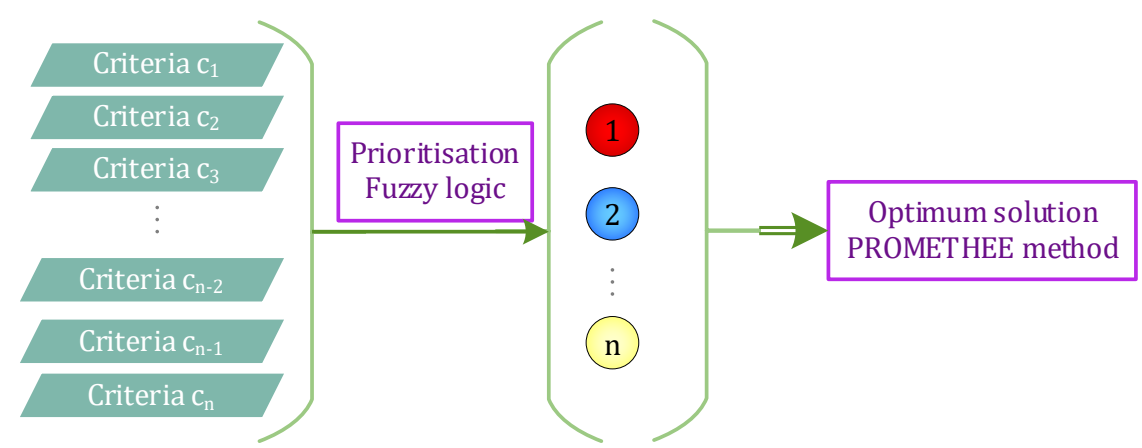

Fig. 5. Selection principle

\section{Conclusion}

Representing one of the key pillars of Industry 4.0, 3D printing has become an important process in digital transformation, as it has the ability to transform a digital format into a physical object, requiring only a 3D printer, raw material and digital format. Thus, 3D printing does not require a whole line of manufacturing, high-performance machineries or tools and devices to make the final product.

Additive manufacturing also plays an important role in sustainable development, due to the reduction of waste as well as the saving of electricity. Additive technology is also on a fast track to maturity, with different businesses developing.

3D printing brings flexibility in design, production, and services in many industries. As speed, quality and materials improve, those who exploit the new possibilities will benefit. There are production units in which it is made to order for a huge variety of purchases and the delivery time is short. The flexibility of custom 3D printing production means that there are printers available, materials and models suitable for any customer order. These problems may be solved by the informatic application/ software created by authors, this facilitating the choice of printing technologies, an ethnically adequate printer, and optimal technological parameters.

\section{References}

1. Tin-Chih Toly Chen (2020): 3D Printing and Ubiquitous Manufacturing. Springer, ISBN 978-3-030-49150-5 (e-book), https://doi.org/10.1007/978-3-030-49150-5

2. Carlota V. (2019): How to choose a 3D software for 3D printing: Experts give their advice! Available at: https://www.3dnatives.com/en/3d-modeling-sofware-050620194/\#! Accessed: 2021-10-05

3. Enfroi A. (2021): 17 Best 3D Printing Software of 2021 (CAD and Modeling Tools). Available at: https://www.adamenfroy.com/3d-printing-software. Accessed: 2021-10-12

4. Šljivic M., Pavlovic A., Kraišnik M., Ilić J. (2019): Comparing the accuracy of 3D slicer software in printed end-use parts. IOP Conf. Series: Materials Science and Engineering, ISSN 1757-899X, Vol. 659, article no. 012082, https://iopscience.iop.org/article/10.1088/1757-899X/659/1/012082/pdf

5. Prout K. (2020): 3D Printer User Guide: A Complete Step by Step User Manual for Understanding the Fundamentals of 3D Printing, How to Maintain and Troubleshoot Common Difficulties. ISBN 979-8-583-50366-7

6. https://cdn.thomasnet.com/ccp/00399914/221437.pdf. Accessed: 2021-07-20

7.https://3dgence.com/?gclid=Cj0KCQiAzMGNBhCyARIsANpUkz0650qpSsa6GrW9fLaHi1g2X\%20GMD25hlOUY Q49rTvzRnch njB-WTAaAq-rEALw wcB. Accessed: 2021-07-20

8. 3D Printing vs CNC Machining: Which is best for prototyping? https://www.3dnatives.com/en/3d-printing-vscnc-160320184/\#! Accessed: 2021-08-17

9. The Importance of 3D Printing in Industry 4.0. https://www.3dnatives.com/en/3d-printing-in-industry-4-0150220215/\#! Accessed: 2021-11-02

10. Greene T. (2017): The Role of 3D Printing in Factory 4.0. IDC Analyse the Future, https://www.stratasys.co.kr/$\angle$ media/files/white-papers-new/idc---stratasys-white-paper.pdf. IDC \#US43373217, Accessed: 2021-04-17 